Research Paper

\title{
HGF, sIL-6R and TGF- $\beta$, Play a Significant Role in the Progression of Multiple Myeloma
}

\author{
Artur Jurczyszyn $^{1}{ }^{\bowtie}$, Jacek Czepiel2 ${ }^{2}$, Grażyna Biesiada², Joanna Gdula-Argasińska3 ${ }^{3}$, Dorota Cibor², Danuta \\ Owczarek $^{2}$, William Perucki ${ }^{4}$, Aleksander B. Skotnicki ${ }^{1}$ \\ 1. Department of Haematology, University Hospital, Kraków, Poland; \\ 2. Department of Gastroenterology, Hepatology and Infectious Diseases, Jagiellonian University Medical College, Kraków, Poland; \\ 3. Department of Radioligands, Faculty of Pharmacy, Jagiellonian University Medical College, Kraków, Poland; \\ 4. Students' Scientific Society, Jagiellonian University Medical College, Kraków, Poland.
}

$\square$ Corresponding author: Artur Jurczyszyn, MD, PhD. Oddział Hematologii, Szpital Uniwersytecki, ul. Kopernika 17, 31-501 Kraków, Polska. Phone: 12 - 424-76-00, fax: 12-424-74-26 e-mail: mmjurczy@cyf-kr.edu.pl.

( ) Ivyspring International Publisher. This is an open-access article distributed under the terms of the Creative Commons License (http://creativecommons.org/ licenses/by-nc-nd/3.0/). Reproduction is permitted for personal, noncommercial use, provided that the article is in whole, unmodified, and properly cited.

Received: 2014.03.31; Accepted: 2014.05.22; Published: 2014.06.II

\begin{abstract}
Background. In the last few years, it has been widely reported that proinflammatory and angiogenic cytokines are important for the development and progression of multiple myeloma (MM).

Objectives. To further validate and acquire more insight into this view we decided to check whether plasma levels of certain cytokines and their soluble receptors differ between MM patients and healthy subjects.

Patients and Methods. The study was conducted in $76 \mathrm{MM}$ patients aged 22 to 77 years $(60 \pm 10$ years) and 35 healthy controls aged 20 to 63 years (33 10 years). Plasma levels of interleukin- 6 (IL-6), b-fibroblast growth factor (b-FGF), hepatocyte growth factor (HGF), vascular endothelial growth factor (VEGF) and transforming growth factor- $\beta_{1}\left(T G F-\beta_{1}\right)$, as well as soluble receptors for IL-6 (sIL-6R) and VEGF (sVEGF-R2) were measured using enzyme-linked immunosorbent assay (ELISA).

Results. Significantly higher plasma levels of IL-6 (I3.65 $\pm 42.6 \mathrm{I}$ vs. I. $04 \pm 1.12 \mathrm{pg} / \mathrm{ml}, p=0.006)$, HGF $(2174 \pm 2714$ vs. $648 \pm 130 \mathrm{pg} / \mathrm{ml}, p<0.00 \mathrm{I})$, b-FGF $(7.92 \pm 10.78$ vs. $2.54 \pm 5.38 \mathrm{pg} / \mathrm{ml}, p<0.00 \mathrm{l})$ and sIL-6R (37.I $\pm \mid 4.2$ vs. $25.3 \pm 6.4 \mathrm{ng} / \mathrm{ml}, p=0.003)$ were observed in MM patients vs. healthy controls, respectively. Plasma sVEGF-R2 was significantly lower in MM patients than in controls (75 I $8 \pm 2$ I I 9 vs. $8725 \pm 128 \mathrm{I} \mathrm{pg} / \mathrm{ml}$, respectively; $p<0.00 \mathrm{I}$ ). We observed an inverse correlation between length of treatment and the level of sIL-6R, and TGF- $\beta_{1}$ in plasma.

Conclusions. Plasma levels of HGF, b-FGF, IL-6 and sIL-6R in MM patients were higher when compared to the control group. Antineoplastic therapy leads to a time-dependent decrease in plasma levels of sIL-6R, and TGF- $\beta_{1}$ in MM patients. Blood plasma level of HGF is an optimal measure to differentiate patients in whom disease is progressing versus patients who respond to therapy.
\end{abstract}

Key words: b-FGF, cytokines, HGF, interleukin-6, multiple myeloma.

\section{Introduction}

Recent studies have confirmed the importance of soluble cytokines and their receptors in the biology of multiple myeloma (MM) [1-3]. The principal mechanism of action of interleukin-6 (IL-6) in MM is most likely the inhibition of apoptosis of myeloma cells. It has been shown that the level of soluble receptors for IL-6 (sIL-6R) is elevated in myeloma patients compared to healthy subjects, and its level correlates with 
disease severity [3,4]. Currently, the serum level of sIL-6R is considered to be one of the prognostic factors in MM [4]. Vascular endothelial growth factor (VEGF) is one of the strongest drivers of angiogenesis. In MM, the binding of VEGF with its receptors, VEGF-R1 and VEGF-R2, induces angiogenesis and leads to exponential growth of the tumour. Furthermore, with the activation of these receptors, there is increased expression of integrins on the cell surface, which facilitates adhesion and migration $[6,7,8]$. In $\mathrm{MM}$, the serum level of basic fibroblast growth factor (b-FGF) increases with disease progression. It was also found that myeloma cells express surface receptor FGF-R3 (which is not found on normal lymphoid cells), divide more rapidly and undergo apoptosis less frequently than cells without FGF-R3. Effective antiproliferative treatment often causes a reduction in b-FGF levels in the serum of patients with MM $[1,9,10]$. Transforming growth factor- $\beta_{1}\left(\right.$ TGF- $\left.\beta_{1}\right)$ is synthesized by almost all cells of the body. The increased microvascular network in the bone marrow of patients with $\mathrm{MM}$ is likely the result of the plasma secretion of TGF- $\beta_{1}$, which stimulates the release of platelet derived growth factor and thereby enhances angiogenesis [11]. Hepatocyte growth factor (HGF) has mitogenic, chemotactic, and morphogenic properties. It has a significant effect on the morphogenesis of new blood vessels and bone marrow stroma, and it stimulates the synthesis of angiogenic factors. Elevated levels of HGF in the serum of patients with MM is associated with an unfavourable prognosis. $\mathrm{Nu}-$ merous studies have shown that HGF is involved in the progression of $\mathrm{MM}$, including damage to bone, angiogenesis, and myeloma cell adhesion to bone marrow stroma [12,13]. Studies indicate the importance of the HGF-c-MET axis in the stimulation of proliferation and inhibition of apoptosis in MM cells $[4,15,16]$.

The aim of this study was to compare the plasma levels of cytokines IL-6, VEGF, b-FGF, TGF- $\beta_{1}$, HGF, and soluble receptors sIL-6R and sVEGF-R2 between patients with $\mathrm{MM}$ and healthy volunteers.

\section{Patients and methods}

\section{Clinical characteristics of the study group}

The study comprised 76 patients aged 22 to 77 years (mean age 60 years, $\mathrm{SD} \pm 10$ ) with MM treated at the Department of Haematology, University Hospital, Krakow, Poland. The control group consisted of 35 healthy volunteers aged 20 to 63 years (mean age 33 years, $S D \pm 10$ ). Both test and control groups were similar with respect to gender distribution. The group of patients with MM included 38 women and 38 men, $\mathrm{F} / \mathrm{M}$ ratio $=1$. The control group consisted of 19 women $(54.3 \%)$ and 16 men $(45.7 \%) \mathrm{F} / \mathrm{M}$ ratio $=1.2$. The diagnosis of MM was based on cytologic examination of bone marrow aspirate revealing at least 10\% plasmocytes, the presence of monoclonal proteins in serum or urine, and bone osteolytic lesions. Patients with MM were divided into 2 groups, designated $\mathrm{N}$ for newly diagnosed, previously untreated, and $S$ for patients undergoing antiproliferative treatment. Group N consisted of 29 patients (38.2\%), while group $\mathrm{S}$ consisted of 47 people $(61.8 \%)$. We subdivided group $S$ into three groups, based on length of treatment: S1 included patients undergoing treatment for 1 to 2 years $(n=13), S 2$ comprised patients undergoing treatment for 2 to 3 years $(n=11)$, and S3 consisted of patients undergoing treatment for longer than 3 years $(n=23)$. Additionally, any patient in group $S$ undergoing treatment for more than a year was evaluated for response to antiproliferative therapy. Patients with MM were treated according to the guidelines of the Polish Myeloma Group. For patients under 65 years of age, first line treatment consisted of the CTD protocol (cyclophosphamide, thalidomide, and dexamethasone) followed by CTX and G-CSF combined with the auto-PBSCT procedure. Throughout treatment we continued thalidomide. In cases of disease recurrence, treatment consisted of bortezomib or lenalidomide in many cases. Patients over 65 years of age were treated either with the MPT (melphalan, prednisone, and thalidomide) or VMP (bortezomib, melphalan and prednisone) protocols. In cases of disease progression, lenalidomide and dexamethasone were given [17]. We evaluated whether there was progression of disease, resistance to treatment, or if treatment had a positive effect. These analyses were based on: assessment of bone marrow (the percentage of plasma cells in bone marrow biopsy), protein parameters (serum protein electrophoresis), biochemical parameters (serum C-reactive protein - CRP, $\beta 2$ microglobulin, calcium), and complete blood count. During our testing we were unable to evaluate the clinical outcome of treatment in 6 patients, and therefore testing was conducted on the remaining group of 41 patients. Of these remaining patients 23 positively responded to treatment while 18 patients showed progressive MM which was resistant to therapy. The study was approved by the local Ethics Committee.

\section{Blood and plasma analysis}

Blood samples were collected between 7:30 and 8:30 hours in sterile Vacutainer tubes (Becton Dickinson, New Jersey, USA) which contained an anticoagulant (EDTA). The tubes were then centrifuged for 10 minutes at 1,000 RPM. Plasma was pipetted into sterile tubes (Nunc, Roskilde, Denmark) and stored at $-70^{\circ} \mathrm{C}$ until analysis was performed. Biochemical as- 
says of lactate dehydrogenase (LDH), blood urea, creatinine, total calcium concentration in both groups and CRP, $\beta_{2}$ microglobulins, serum protein electrophoresis in MM group were performed using standard methods. Results of blood counts were obtained via photo-optical and conductivity methods using a Cell-Dyn 1700 analyzer (Abbott, Abbott Park, USA). The plasma levels of VEGF, sVEGF-R2, IL-6, sIL-6R, b-FGF, HGF, and TGF- $\beta_{1}$ were measured using ELISA assays (Quantikine, R\&D Systems, Minneapolis, MN., USA).

\section{Statistical methods}

Results were subjected to statistical analysis. The normality of the distribution was tested using the Shapiro-Wilk test. We used Student's t-test for the analysis of independent variables, and the $U$ Mann-Whitney test for the analysis of dependent variables. All calculations were performed using STATISTICA 10 PL software (StatSoft, Inc., USA) licensed to Jagiellonian University. Only results which had a $p$ value $<0.05$ were considered statistically significant.

\section{Result}

Plasma levels of cytokines, their soluble receptors, and the assessment of biochemical parameters in patients with MM versus the control group are presented (Tables 1 and 2). Elevations of HGF, b-FGF, IL-6, and sIL-6R were observed in the blood plasma of patients with $\mathrm{MM}$ as compared to the control group, whereas the plasma level of sVEGF-R2 was lower compared to the control group. Analyses revealed differences in the clinical values of erythrocytes, haemoglobin, haematocrit, platelet count, urea, creatinine, and LDH activity in serum between MM patients and controls. We also analyzed concentrations of cytokines and their soluble receptors in MM patients paying attention to differences that may be attributed to age and sex. The only differences noted between the sexes was the concentration of b-FGF, which was twice as high in males when compared with women (Table 3). We did not, however, observe any statistically significant differences attributed to age (Additional file 1: supplementary Table 1). We compared the levels of cytokines and soluble cytokine receptors, depending on the application and duration of disease treatment. Higher levels of TGF- $\beta 1$ were observed in group $\mathrm{N}$ patients when compared to group S (Table 4). We further analyzed patients depending on duration of therapy (Table 5). During initial therapy, mean plasma IL-6 levels decreased three fold compared to pre-treatment levels. However, in patients who were treated the longest, plasma levels of IL-6 rose to levels greater than those observed prior to initiation of treatment. Conversely, we observed a drop in plasma levels of sIL-6R and TGF- $\beta_{1}$ as duration of disease and treatment increased. Decreased levels of VEGF, HGF, and b-FGF were noticed after initiation of therapy. Values of sVEGF-R2 were similar in all analyzed subgroups. We evaluated whether there was a relationship between length of therapy and tested cytokines/soluble cytokine receptors in the whole group of patients with MM. We observed an inverse correlation between length of treatment and the concentration of sIL-6R, and TGF- $\beta 1$ in plasma (Table 6). Furthermore, we compared the level of cytokines and soluble cytokine receptors, at various stages of disease progression. The analysis shows that the most useful parameter in evaluating the progression of multiple myeloma is the plasma level of HGF (Table 7).

Table I. Cytokines, their soluble receptors and routine laboratory plasma levels in multiple myeloma patients and healthy controls.

\begin{tabular}{|c|c|c|c|c|c|}
\hline \multirow[t]{3}{*}{ Parameter } & \multicolumn{4}{|c|}{ Study group } & \multirow[t]{3}{*}{$p$-value } \\
\hline & \multicolumn{2}{|c|}{ Patients with MM } & \multicolumn{2}{|c|}{ Healthy controls } & \\
\hline & $\mathrm{n}$ & mean $\pm S D$ & $\mathrm{n}$ & mean $\pm S D$ & \\
\hline IL-6 (pg/ml) & 65 & $13.65 \pm 42.61$ & 35 & $1.04 \pm 1.12$ & 0.006 \\
\hline sIL-6R (ng/ml) & 65 & $37.1 \pm 14.2$ & 35 & $25.3 \pm 6.4$ & 0.003 \\
\hline VEGF (pg/ml) & 65 & $56.8 \pm 46.7$ & 35 & $49.9 \pm 49.9$ & NS \\
\hline sVEGF-R2 (pg/ml) & 65 & $7518 \pm 2119$ & 35 & $8725 \pm 1281$ & $<0.001$ \\
\hline HGF (pg/ml) & 76 & $2174 \pm 2714$ & 35 & $648 \pm 130$ & $<0.001$ \\
\hline b-FGF (pg/ml) & 76 & $7.92 \pm 10.78$ & 35 & $2.54 \pm 5.38$ & $<0.001$ \\
\hline TGF- $\beta_{1}(\mathrm{ng} / \mathrm{ml})$ & 76 & $12.41 \pm 6.64$ & 35 & $13.72 \pm 8.17$ & NS \\
\hline $\mathrm{WBC}(\mathrm{K} / \mu \mathrm{l})$ & 66 & $5.56 \pm 2.65$ & 27 & $5.91 \pm 1.38$ & NS \\
\hline $\operatorname{RBC}(\mathrm{M} / \mu \mathrm{l})$ & 66 & $3.53 \pm 0.70$ & 27 & $4.80 \pm 0.67$ & $<0.001$ \\
\hline $\mathrm{Hb}(\mathrm{g} / \mathrm{dl})$ & 66 & $11.2 \pm 2.04$ & 27 & $14.3 \pm 1.94$ & $<0.001$ \\
\hline Hct $(\%)$ & 66 & $32.7 \pm 6.24$ & 27 & $42.6 \pm 5.5$ & $<0.001$ \\
\hline $\operatorname{PLT}(\mathrm{K} / \mu \mathrm{l})$ & 66 & $200.8 \pm 86.7$ & 27 & $270.1 \pm 72.4$ & $<0.001$ \\
\hline Urea (mmol/l) & 42 & $8.15 \pm 5.98$ & 7 & $5.11 \pm 1.75$ & 0.011 \\
\hline Creatinine $(\mu \mathrm{mol} / \mathrm{l})$ & 42 & $128.5 \pm 141.7$ & 7 & $74.7 \pm 10.99$ & 0.020 \\
\hline Calcium (mmol/l) & 43 & $2.37 \pm 0.35$ & 7 & $2.35 \pm 0.22$ & NS \\
\hline LDH (U/1) & 37 & $431.4 \pm 275.39$ & 7 & $299.7 \pm 55.79$ & 0.012 \\
\hline
\end{tabular}

b-FGF, b-fibroblast growth factor; Hb, haemoglobin; Hct, haematocrit; HGF, hepatocyte growth factor; IL-6, interleukin-6; LDH, lactate dehydrogenase; MM, multiple myeloma; NS, not significant; PLT, blood platelets; RBC, red blood cells; sIL-6R, soluble IL-6 receptor; SD, standard deviation; sVEGF-R2, soluble VEGF receptor; TGF- $\beta_{1}$, transforming growth factor- $\beta_{1}$; VEGF, vascular endothelial growth factor; WBC, white blood cells.

Table 2. Results of electrophoresis, CRP level, blood serum

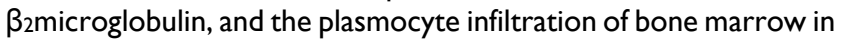
MM patients.

\begin{tabular}{lll}
\hline Parameter & \multicolumn{2}{c}{ Patients with MM } \\
\cline { 2 - 3 } & $\mathrm{n}$ & mean \pm SD \\
\hline Total Protein (g/l) & 68 & $89.0 \pm 20.8$ \\
Albumin (g/l) & 68 & $45.8 \pm 10.4$ \\
Alpha 1 globulin (\%) & 67 & $3.6 \pm 1.8$ \\
Alpha 2 globulin (\%) & 67 & $10.6 \pm 7.9$ \\
Beta globulin (\%) & 67 & $12.2 \pm 9.2$ \\
Gamma globulin (\%) & 67 & $25.3 \pm 15.3$ \\
CRP (mg/l) & 17 & $14.95 \pm 21.65$ \\
$\beta_{2}$ microglobulin (mg/1) & 18 & $3.35 \pm 1.76$ \\
Plasmocyte infiltration of bone marrow (\%) & 37 & $45.8 \pm 27.8$ \\
\hline CRP C-reactive protein; MM, multiple myeloma; SD, standard deviation.
\end{tabular}

CRP, C-reactive protein; MM, multiple myeloma; SD, standard deviation. 
Table 3. Cytokines and their soluble receptors in male and female MM patients.

\begin{tabular}{lllll}
\hline & sex & $\mathrm{n}$ & mean $\pm \mathrm{SD}$ & $p$-value \\
\hline IL-6 $(\mathrm{pg} / \mathrm{ml})$ & $\mathrm{F}$ & 31 & $14.4 \pm 43.2$ & 0.596 \\
& $\mathrm{M}$ & 34 & $12.9 \pm 42.7$ & \\
sIL-6R $(\mathrm{ng} / \mathrm{ml})$ & $\mathrm{F}$ & 31 & $39.3 \pm 16.8$ & 0.975 \\
& $\mathrm{M}$ & 34 & $35.1 \pm 11.2$ & \\
VEGF $(\mathrm{pg} / \mathrm{ml})$ & $\mathrm{F}$ & 31 & $58.4 \pm 45.7$ & 0.519 \\
& $\mathrm{M}$ & 34 & $55.4 \pm 48.1$ & \\
sVEGF-R2 $(\mathrm{pg} / \mathrm{ml})$ & $\mathrm{F}$ & 31 & $7577.4 \pm 2120.2$ & 0.542 \\
& $\mathrm{M}$ & 34 & $7464.0 \pm 2148.4$ & \\
HGF $(\mathrm{pg} / \mathrm{ml})$ & $\mathrm{F}$ & 38 & $2021.3 \pm 1783.0$ & 0.897 \\
& $\mathrm{M}$ & 38 & $2327.8 \pm 3421.8$ & \\
b-FGF $(\mathrm{pg} / \mathrm{ml})$ & $\mathrm{F}$ & 38 & $5.42 \pm 7.13$ & 0.020 \\
& $\mathrm{M}$ & 38 & $10.42 \pm 13.11$ & \\
TGF- $\beta_{1}(\mathrm{ng} / \mathrm{ml})$ & $\mathrm{F}$ & 38 & $11.61 \pm 5.87$ & 0.466 \\
& $\mathrm{M}$ & 38 & $13.24 \pm 7.33$ & \\
\hline
\end{tabular}

b-FGF, b-fibroblast growth factor; F, female; HGF, hepatocyte growth factor; IL-6, interleukin-6; M, male; MM, multiple myeloma; sIL-6R, soluble IL-6 receptor; $\mathrm{SD}$, standard deviation; sVEGF-R2, soluble VEGF receptor; TGF- $\beta_{1}$, transforming growth factor- $\beta_{1}$; VEGF, vascular endothelial growth factor;

Table 4. Comparison of levels of cytokines and soluble cytokine receptors in the treated versus untreated groups.

\begin{tabular}{|c|c|c|c|c|c|}
\hline \multirow[t]{2}{*}{ Parameter } & \multicolumn{2}{|c|}{$\begin{array}{c}\text { Patients with MM, } \\
\text { group N }\end{array}$} & \multicolumn{2}{|c|}{$\begin{array}{c}\text { Patients with MM, } \\
\text { group S }\end{array}$} & \multirow[t]{2}{*}{$\mathrm{p}$} \\
\hline & $\mathrm{n}$ & $x \pm S D$ & $\mathrm{n}$ & $x \pm S D$ & \\
\hline IL-6 (pg/ml) & 22 & $17.2 \pm 20.7$ & 43 & $11.8 \pm 38.5$ & NS \\
\hline sIL-6R (ng/ml) & 22 & $42.9 \pm 15.9$ & 43 & $34.1 \pm 12.4$ & NS \\
\hline VEGF (pg/ml) & 22 & $64.5 \pm 52.6$ & 43 & $52.9 \pm 43.4$ & NS \\
\hline sVEGF-R2 (pg/ml) & 22 & $7734 \pm 2007$ & 43 & $7407 \pm 2188$ & NS \\
\hline $\mathrm{HGF}(\mathrm{pg} / \mathrm{ml})$ & 29 & $2007 \pm 1660$ & 47 & $2277 \pm 3210$ & NS \\
\hline $\mathrm{b}-\mathrm{FGF}(\mathrm{pg} / \mathrm{ml})$ & 29 & $7.44 \pm 11.11$ & 47 & $8.21 \pm 10.69$ & NS \\
\hline TGF- $\beta_{1}(\mathrm{ng} / \mathrm{ml})$ & 29 & $14.24 \pm 7.00$ & 46 & $11.26 \pm 6.20$ & 0.025 \\
\hline
\end{tabular}

b-FGF, b-fibroblast growth factor; HGF, hepatocyte growth factor; IL-6, interleukin-6; MM, multiple myeloma; $\mathrm{N}$, newly diagnosed patients, previously untreated; NS, not significant; $S$, patients remaining in treatment; sIL- 6R, soluble IL-6 receptor; SD, standard deviation; SVEGF-R2, VEGF soluble receptor; TGF- $\beta_{1}$, trans-

forming growth factor- $\beta_{1}$; VEGF, vascular endothelial growth factor.

Table 6. Analysis of correlation between duration of therapy and studied cytokines.

\begin{tabular}{llll}
\hline & $\mathrm{n}$ & $\mathrm{r}$ Spearman & $\mathrm{p}$ \\
\hline IL-6 $(\mathrm{pg} / \mathrm{ml})$ & 58 & 0.007 & NS \\
sIL-6R $(\mathrm{ng} / \mathrm{ml})$ & 58 & -0.304 & 0.02 \\
VEGF $(\mathrm{pg} / \mathrm{ml})$ & 58 & -0.243 & NS \\
sVEGF-R2 $(\mathrm{pg} / \mathrm{ml})$ & 58 & -0.100 & NS \\
HGF $(\mathrm{pg} / \mathrm{ml})$ & 68 & 0.009 & NS \\
b-FGF $(\mathrm{pg} / \mathrm{ml})$ & 68 & -0.083 & NS \\
TGF- $\beta 1(\mathrm{ng} / \mathrm{ml})$ & 68 & -0.253 & 0.04
\end{tabular}

b-FGF, b-fibroblast growth factor; HGF, hepatocyte growth factor; IL-6, interleukin-6; NS, not significant; sIL-6R, soluble IL-6 receptor; sVEGF-R2, soluble VEGF receptor; TGF- $\beta_{1}$, transforming growth factor- $\beta_{1}$; VEGF, vascular endothelial growth factor.
Table 5. Comparison of plasma levels of cytokines and soluble cytokine receptors in patient subgroups according to treatment duration.

\begin{tabular}{|c|c|c|c|}
\hline Parameter & Group & $\mathrm{n}$ & mean $\pm \mathrm{SD}$ \\
\hline \multirow[t]{4}{*}{ IL-6 (pg/ml) } & $\mathrm{N}$ & 21 & $18.03 \pm 51.83$ \\
\hline & S1 & 12 & $7.21 \pm 7.58$ \\
\hline & S2 & 9 & $6.34 \pm 7.96$ \\
\hline & S3 & 16 & $19.80 \pm 62.30$ \\
\hline \multirow[t]{4}{*}{ sIL-6R (ng/ml) } & $\mathrm{N}$ & 21 & $43.79 \pm 15.72$ \\
\hline & S1 & 12 & $34.02 \pm 12.77$ \\
\hline & S2 & 9 & $34.02 \pm 13.72$ \\
\hline & S3 & 16 & $32.92 \pm 11.29$ \\
\hline \multirow[t]{4}{*}{ VEGF (pg/ml) } & $\mathrm{N}$ & 21 & $64.87 \pm 53.90$ \\
\hline & S1 & 12 & $71.69 \pm 64.67$ \\
\hline & S2 & 9 & $39.27 \pm 29.72$ \\
\hline & S3 & 16 & $40.68 \pm 23.76$ \\
\hline \multirow[t]{4}{*}{ sVEGF-R2 (pg/ml) } & $\mathrm{N}$ & 21 & $7652 \pm 2019$ \\
\hline & S1 & 12 & $7874 \pm 2545$ \\
\hline & S2 & 9 & $6985 \pm 1706$ \\
\hline & S3 & 16 & $7278 \pm 2143$ \\
\hline \multirow[t]{4}{*}{$\operatorname{HGF}(\mathrm{pg} / \mathrm{ml})$} & $\mathrm{N}$ & 28 & $2001 \pm 1690$ \\
\hline & S1 & 13 & $2570 \pm 3489$ \\
\hline & S2 & 11 & $2186 \pm 2306$ \\
\hline & S3 & 16 & $2073 \pm 4089$ \\
\hline \multirow[t]{4}{*}{ b-FGF (pg/ml) } & $\mathrm{N}$ & 28 & $7.71 \pm 11.22$ \\
\hline & S1 & 13 & $10.54 \pm 15.83$ \\
\hline & S2 & 11 & $7.10 \pm 5.97$ \\
\hline & S3 & 16 & $5.68 \pm 6.07$ \\
\hline \multirow[t]{4}{*}{ TGF- $\beta_{1}(\mathrm{ng} / \mathrm{ml})$} & $\mathrm{N}$ & 28 & $14.11 \pm 7.09$ \\
\hline & S1 & 13 & $11.91 \pm 6.06$ \\
\hline & S2 & 11 & $12.39 \pm 7.95$ \\
\hline & S3 & 16 & $9.60 \pm 4.38$ \\
\hline
\end{tabular}

b-FGF, b-fibroblast growth factor; HGF, hepatocyte growth factor; IL-6, interleukin-6; MM, multiple myeloma; $\mathrm{N}$, newly diagnosed patients, previously untreated, NS, not significant; $\mathrm{S} 1$, patients treated from 1 to 2 years; S2, patients treated from 2 to 3 years; S3, patients treated for longer than 3 years; sIL-6R, soluble IL-6 receptor; $\mathrm{SD}$, standard deviation; sVEGF-R2, soluble VEGF receptor; TGF- $\beta_{1}$, transforming growth factor- $\beta_{1}$; VEGF, vascular endothelial growth factor.

Table 7. Levels of cytokines and soluble cytokine receptors in various stages of disease progression.

\begin{tabular}{|c|c|c|c|c|c|}
\hline \multirow[t]{3}{*}{ Parameter } & \multicolumn{4}{|c|}{$\begin{array}{l}\text { Patients with MM treated with antiproliferative } \\
\text { therapy }\end{array}$} & \\
\hline & \multicolumn{2}{|c|}{$\begin{array}{l}\text { Without disease progres- } \\
\text { sion }\end{array}$} & \multicolumn{2}{|c|}{$\begin{array}{l}\text { With disease pro- } \\
\quad \text { gression }\end{array}$} & \\
\hline & $\mathrm{n}$ & mean $\pm S D$ & $\mathrm{n}$ & mean $\pm \mathrm{SD}$ & \\
\hline IL-6 (pg/ml) & 20 & $4.14 \pm 5.75$ & 18 & $19.59 \pm 58.15$ & NS \\
\hline sIL-6R (ng/ml) & 20 & $31.2 \pm 9.1$ & 18 & $38.4 \pm 15.4$ & NS \\
\hline VEGF (pg/ml) & 20 & $47.4 \pm 33.9$ & 18 & $55.2 \pm 54.0$ & NS \\
\hline sVEGF-R2 (pg/ml) & 20 & $7591 \pm 1612$ & 18 & $7066 \pm 2682$ & NS \\
\hline $\mathrm{HGF}(\mathrm{pg} / \mathrm{ml})$ & 23 & $1283 \pm 1583$ & 18 & $3555 \pm 4498$ & $<0.001$ \\
\hline b-FGF (pg/ml) & 23 & $6.46 \pm 9.17$ & 18 & $9.71 \pm 12.51$ & NS \\
\hline TGF- $\beta_{1}(\mathrm{ng} / \mathrm{ml})$ & 22 & $10.84 \pm 6.28$ & 18 & $12.33 \pm 6.33$ & NS \\
\hline
\end{tabular}

time-dependent decrease in plasma levels of sIL-6R, and TGF- $\beta 1$ in MM patients. The analysis shows that the most useful parameter in evaluating the progression of multiple myeloma is the plasma level of HGF. The data we analyzed showed that plasma concentrations of the selected cytokines are another element 
which allows clinicians to evaluate disease progression as well as the effectiveness of treatment. Identifying patients, in whom treatment is less effective may be one reason to suggest a change in therapy, however this requires further study. Our study was limited by age differences in the populations studied. A correlation analysis of the studied age-dependent parameters in both groups demonstrated that age does not affect any of these parameters in patients with $\mathrm{MM}$, and demonstrated that the effect is directly proportional to HGF and VEGF levels in controls (Additional file 1: supplementary Table 2). This observation led to our conclusion that HGF level played a significantly greater role than age did on the results observed.

Increased cytokine secretion by bone marrow stroma often plays a major role in the pathogenesis of some of the clinical signs of MM, such as bone disease. In our study, a statistically significant higher level of HGF, b-FGF, IL-6, and sIL-6R was observed in the blood plasma of MM patients as compared to the control group. Many studies have demonstrated that plasma levels of IL-6 and sIL-6R are elevated in patients with $\mathrm{MM}$ and correlate with the severity of the cancer [1,18-20]. Bataille et al. showed that in patients with stage III MM, based on the Durie and Salmon classification, levels of IL-6 were significantly higher compared to patients with stage I and II disease. In addition, it was noted that elevated levels of IL-6 in serum was a good predictor of the severity of the disease [18]. Rawstron et al. examined the expression of the CD126 antigen (a subunit of the receptor for IL-6), and found that it is only present in MM cells; it is not expressed in normal plasma cells. IL-6 leads to tumour growth, not only through direct stimulation of cell proliferation, but also via the inhibition of apoptosis of tumour plasma cells [1, 21]. Kyrstsonis et al. studied the levels of IL-6 in the serum of healthy individuals and patients with multiple myeloma treated with chemotherapy. The level of IL-6 in MM patients, which was significantly elevated before treatment started, decreased to undetectable values at the time of hematologic remission. A gradual increase in IL-6 was observed if relapse occurred [22]. In our study we observed that anti-proliferative treatment has a significant effect on sIL-6 plasma levels. The plasma level of this cytokine showed a negative correlation with the duration of treatment. Changes in the level of IL-6 in MM during treatment reflect the current ability to control the condition. The level of IL-6 decreases in the first years of treatment (group S1), when treatment is most effective. However, it increases with disease duration (S3), showing that MM progression is inevitable.

VEGF and other proangiogenic cytokines play a vital role in the neovascularization of the bone marrow of patients with MM. Vacca et al. measured the area occupied by the small blood vessels in bone marrow specimens from MM patients and compared them to healthy individuals. The area of small blood vessels was significantly larger in patients with active MM compared to patients with an inactive form of the disease, monoclonal gammopathy of undetermined significance (MGUS), or healthy subjects $[23,24]$. In our study plasma levels of b-FGF and VEGF in patients with MM were higher compared to the control group, but this difference was statistically significant only for b-FGF. The role of b-FGF in the pathogenesis of MM has not yet been fully described. Plowright et al. observed ectopic expression of FGFR-3 in approximately $25 \%$ of patients with MM [9]. It was observed that when cells expressing FGFR-3 were autonomous of IL-6, there was a reduced level of apoptosis and enhanced proliferative response following stimulation with IL-6. In the presence of FGF-9 and FGFR-3 ligand, test cells rapidly proliferated and were more viable than cells with normal expression of FGFR-3. Di Raimondo et al. divided patients into two groups based on the stage of their cancer (disease confined to the bone marrow vs. extramedullary location) [25]. In both groups of patients significantly elevated levels of VEGF and b-FGF were observed in the bone marrow as compared to serum. Elevated levels of VEGF and b-FGF in the bone marrow and serum of patients with MM was also reported by $\mathrm{Zhu}$ et al. [26]. The level of these cytokines was significantly increased in the bone marrow compared to peripheral blood, which indicates that the bone marrow is likely to be a major site of production. Many researchers have confirmed that pathological plasma cells secrete factors that stimulate angiogenesis [27-29]. In our study we observed that the mean plasma levels of sVEGF-R2 were decreased in MM patients compared to the control group. It seems that the formation of new blood vessels is probably increased in the bone marrow stroma of MM patients when compared to the control group of healthy volunteers. However, sVEGF-R2 is associated with vascular endothelial cells in healthy individuals, which seems to be confirmed by the observations obtained in the present study [27].

Studies regarding the effects of treatment on the degree of angiogenesis in multiple myeloma are inconclusive. Rajkumar et al. compared microvessel density (MVD) in 13 patients before and after treatment with high-dose chemotherapy and subsequent stem cell transplantation [30]. There was no statistically significant reduction in MVD in patients who achieved partial or complete remission after treatment. On this basis it was concluded that increased 
bone marrow vascularity is not associated with regression, even in patients during complete hematologic remission. On the other hand, Sezer et al. and Sjak-Shie et al. reported a reduction of MVD in the bone marrow during chemotherapy [31,32]. Sezer et al. observed decreased MVD index in patients responding to treatment, while the index remained unchanged in the remaining patients [33]. The discrepancies in the results of the individual authors seem to indicate the limited value of MVD as an independent marker of the efficacy of anti-angiogenic therapy. During normal endothelial cell death, MVD decreases, whereas when endothelial cell death is secondary to increased neoplastic cells, MVD increases. Therefore, during anti-angiogenic therapy MVD ratio can decrease, increase or remain the same. A decrease in MVD during anti-angiogenic therapy suggests that the treatment is effective. However, lack of such an effect does not necessarily mean that the drug treatment is ineffective. The above considerations clearly indicate that using MVD as the sole parameter to determine the effectiveness of anti-angiogenic therapy is insufficient. Thus, it is important to search for another marker of angiogenesis that correlates to the clinical effect of treatment. In our study we observed significant negative correlation between bone marrow infiltration by cancer cells and the plasma level of VEGF and TGF- $\beta 1$. When comparing patients in different stages of disease progression, however, variances in these markers showed no statistical significance. Thus, one can conclude that disease progression, i.e., an increase in plasmocyte infiltration of the bone marrow, correlates with a decrease in the level of VEGF and TGF- $\beta 1$ in blood plasma (Additional file 1: supplementary Table 3).

Plasma levels of HGF such as those observed in our study may be useful in determining the prognosis and clinical activity in patients with MM. While examining autocrine stimulation in MM, Borset et al. reported that HGF secreted by the plasma cells stimulates the pathological c-MET receptor present on myeloma cells [14]. In addition to autocrine stimulation, Derksen et al. suggest that HGF is also produced in a paracrine manner by bone marrow stromal cells [33]. Neoplastic plasma cells present in the bone marrow, along with the "network of cytokines" and bone marrow stromal cells are jointly responsible for the destructive changes and osteolytic bone lesions. TGF- $\beta_{1}$ is a cytokine associated with an increase or decrease in bone osteolysis, and also has profibrotic action $[33,34]$. However, in our study the mean plasma levels of TGF- $\beta_{1}$ in MM patients and the control group did not show any statistically significant differences.

Among cytokines that were the best predictors of
MM progression in our study, HGF showed very clear differences between patients grouped by clinical criteria of MM progression. HGF level was approximately two times higher in people with severe progression compared to patients without progression.

\section{Supplementary Material}

Additional File 1:

Supplementary tables 1-3.

http://www.jcancer.org/v05p0518s1.pdf

\section{Competing Interests}

The authors have declared that no competing interest exists.

\section{References}

1. Chou T. Multiple myeloma: recent progress in diagnosis and treatment. J Clin Exp Hematop. 2012; 52: 149-59.

2. Ishikawa $\mathrm{H}$, Tsuyama $\mathrm{N}$, Liu S, et al. Accelerated proliferation of myeloma cells by interleukin-6 cooperating with fibroblast growth factor receptor 3-mediated signals. Oncogene. 2005; 24: 6328-6332.

3. Kovacs E. Interleukin-6 leads to interleukin-10 production in several human multiple myeloma cell lines. Does interleukin-10 enhance the proliferation of these cells? Leuk Res. 2010; 34: 912-916.

4. Tsirakis G, Pappa CA, Kaparou M, et al. The relationship between soluble receptor of interleukin- 6 with angiogenic cytokines and proliferation markers in multiple myeloma. Tumour Biol. 2013; 34: 859-864.

5. Stompór T, Zabłocki M, Pankrac K. Renal involvement in multiple myeloma. Pol Arch Med Wewn. 2012; 122: 443-448.

6. Byzova TV, Goldman CK, Pampori N, et al. A mechanism for modulation of cellular responses to VEGF: activation of the integrins. Mol Cell. 2000; 6: 851-860.

7. Giatromanolaki A, Bai M, Margaritis D, et al. Hypoxia and activated VEGF/receptor pathway in multiple myeloma. Anticanc Res. 2010; 30: 2831-2836.

8. Marković O, Marisavljević D, Cemerikić V, et al. Expression of VEGF and microvessel density in patients with multiple myeloma: clinical and prognostic significance. Med Oncol. 2008; 25: 451-457.

9. Jurczyszyn A, Wolska-Smoleń T, Sobociński M, et al. Serum concentrations of proangiogenic cytokines in patients with multiple myeloma. Acta Haematol Pol. 2003; 34: 40.

10. Plowright EE, Li Z, Bergsagel PL, et al. Ectopic expression of fibroblast growth factor receptor 3 promotes myeloma cell proliferation and prevents apoptosis. Blood. 2000; 95: 992-998.

11. Matsumoto T. Abe M. TGF-ß-related mechanisms of bone destruction in multiple myeloma. Bone. 2011; 48: 129-134

12. Iwasaki $\mathrm{T}$, Hamano $\mathrm{T}$, Ogata $\mathrm{A}$, et al. Clinical significance of vascular endothelial growth factor and hepatocyte growth factor in multiple myeloma. $\mathrm{Br} \mathrm{J}$ Haematol. 2002; 116: 796-802.

13. Sezer O, Jacob C, Eucker J, et al. Serum levels of the angiogenic cytokines basic fibroblast growth factor (bFGF), vascular endothelial growth factor (VEGF) and hepatocyte growth factor (HGF) in multiple myeloma. Eur J Haematol. 2001; 66: 83-88.

14. Borset M, Lien E, Espevik T, et al. Concomitant expression of Hepatocyte Growth Factor/Scatter Factor and the Receptor c-MET in Human Myeloma Cell Lines. J Biol Chem. 1996; 271: 24655-24661.

15. Mahtouk K, Tjin EP, Spaargaren M, et al. The HGF/MET pathway as target for the treatment of multiple myeloma and B-cell lymphomas. Biochem Biophys Acta. 2010; 1806: 208-219.

16. Ro TB, Holien T, Fagerli UM, et al. HGF and IGF-1 synergize with SDF-1a in promoting migration of myeloma cells by cooperative activation of p21-activated kinase. Exp Hematol. 2013; 41: 646-655.

17. Dmoszyńska A, Walter-Croneck A, et al. Guidelines of Polish Myeloma Group concerning diagnosis and therapy of multiple myeloma and other plasmacytic dyscrasias for 2013. Acta Haematologica Polonica. 2013; 44: 3-47.

18. Bataille R, Jourdan M, Zhang XG, et al. Serum levels of interleukin-6, a potent myeloma cell growth factor, as a reflect of disease severity in plasma cell dyscrasias. J Clin Invest. 1989; 84: 2008-2011.

19. Usnarska-Zubkiewicz L, Mazur G, Wróbel T, et al. Expression of serum vascular endothelial growth factor correlates with clinical outcome in multiple myeloma. Pol Arch Med Wewn. 2003;110: 719-724.

20. Usnarska-Zubkiewicz L. Level of interleukin-6 (IL-6), soluble interleukin-6 receptors (sIL-6R) and tumor necrosis factor alpha (TNF-alpha) in untreated and progressing multiple myeloma. Pol Arch Med Wewn. 1998; 99: 30-37. 
21. Rawstron AC, Fenton JA, Ashcroft J, et al. The interleukin-6 receptor alpha-chain (CD126) is expressed by neoplasmatic but not normal plasma cells. Blood. 2000; 96: 3880-3886.

22. Kyrstsonis MC, Dedoussis G, Baxevanis C, et al. Serum interleukin-6 (IL-6) and interleukin-4 (IL-4) in patients with multiple myeloma (MM). Br J Haemat. 1996; 92: 420-422.

23. Vacca A, Ribatti D, Presta M, et al. Bone marrow neovascularization, plasma cell angiogenic potential, and matrix metalloproteinase-2 secretion parallel progression of human multiple myeloma. Blood. 1999; 93: 3064-3073.

24. Vacca A, Ribatti D, Roncali L, et al. Bone marrow angiogenesis and progression in multiple myeloma. Br J Haematol. 1994; 87: 503-508.

25. Di Raimondo F, Azzaro MP, Palumbo G, et al. Angiogenic factors in multiple myeloma: higher levels in bone marrow than in peripheral blood. Haematologica. 2000; 85: 800-805.

26. Zhu AZ, Fleischer M, Bush A. Elevated serum concentrations of fibroblast growth factor (FGF) in patients with multiple myeloma (MM). Proc Annu Meet Am Soc Clin Oncol. 1999; 18A: 155-161.

27. Gupta D, Treon SP, Shima Y, et al. Adhesion of human multiple myeloma cell lines to bone marrow stromal cells stimulates vascular endothelial growth factor secretion: therapeutic application. Leukemia. 2001; 15: 1950-1961.

28. Mądry K, Dwilewicz-Trojaczek J, Suleiman W, Paszkowska-Kowalewska M, Ziarkiewicz-Wróblewska B. Angiogenesis in bone marrow of myelodysplastic syndrome patients. Pol Arch Med Wewn. 2007; 117: 145-150.

29. Wątorek E, Paprocka M, Duś D, Kopeć W, Klinger M. Endostatin and vascular endothelial growth factor: potential regulators of endothelial progenitor cell number in chronic kidney disease. Pol Arch Med Wewn. 2011; 121: 296-302

30. Rajkumar SV, Fonseca R, Witzig TE, et al. Bone marrow angiogenesis in patients achieving complete response after stem cell transplantation for multiple myeloma. Leukemia. 1999; 13: 469-472.

31. Sezer O, Niemöller K, Kaufmann O. Prognostic relevance of bone marrow microvessel density in multiple myeloma. Book of Abstracts, VIIIth International Myeloma Workshop, Banff, Canada; 2001; 156: 80.

32. Sjak-Shie N. The role of angiogenesis and VEGF in multiple myeloma. Abstract Book from Mayo Clinic Symposium "Innovative Research In Multiple Myeloma". Amelia Island, USA. 2001: 210-216.

33. Derksen PWB, de Gorter DJJ, Meijer HP, et al. The hepatocyte growth factor/Met pathway controls proliferation and apoptosis in multiple myeloma. Leukemia. 2003; 17: 764-774.

34. Wójcik KA, Koczurkiewicz P, Michalik M, Sanak M. Transforming growth factor- $\beta 1$-induced expression of connective tissue growth factor is enhanced in bronchial fibroblasts derived from asthmatic patients. Pol Arch Med Wewn. 2012; 122: 326-332. 